\title{
Producción de eritadenina por Lentinula edodes en fermentación en estado sólido
}

\section{Eritadenine production by Lentinula edodes in solid state fermentation}

\author{
Amado Israel Grandes-Blanco 1, Ángel Arturo Cuamatzi-Hernández ${ }^{2}$, Silvia Luna-Suárez ${ }^{3}$, \\ Lilia Sánchez-Minutti ${ }^{2}$ \\ ${ }^{1}$ Universidad Autónoma de Tlaxcala, Facultad de Ciencias de la Salud, Nutrición. Av. Xicoténcatl Norte No. 466, Barrio de San \\ Nicolás, San Pablo del Monte, C.P. 90920, Tlaxcala, México. \\ 2 Universidad Politécnica de Tlaxcala. Avenida Universidad Politécnica No.1, San Pedro Xalcaltzinco, C.P. 90180, Tepeyanco, Tlaxcala, \\ México. \\ ${ }^{3}$ Instituto Politécnico Nacional, Centro de Investigación en Biotecnología Aplicada. Carretera estatal Santa Inés Tecuexcomac- \\ Tepetitla km 1.5, C.P. 90700, Tepetitla, Tlaxcala, México.
}

\section{RESUMEN}

Antecedentes: Lentinula edodes es un hongo comestible de importancia económica en México, produce un compuesto reductor de colesterol llamado eritadenina, el cual se ha obtenido del cuerpo fructífero y micelio del hongo. Su producción se ha evaluado en fermentación sumergida, pero hasta ahora no se ha evaluado la fermentación en estado sólido.

Objetivos: Determinar si la fermentación en estado sólido de L. edodes mejora la producción de eritadenina.

Métodos: Se realizó una fermentación en estado sólido con espuma de poliuretano y un medio enriquecido para determinar la producción de eritadenina, biomasa y consumo de sustrato; la eritadenina se detectó por HPLC-DAD a $260 \mathrm{~nm}$.

Resultados y conclusiones: La biomasa máxima fue de $3.6 \pm 0.11 \mathrm{~g} / \mathrm{L}$, con una tasa de crecimiento específico de $0.015 \pm$ $0.002 \mathrm{~h}^{-1}$. La eritadenina se produjo en la biomasa y se liberó al medio de cultivo; a las $168 \mathrm{~h}$ de incubación se incrementó 2.8 y 2.4 veces, respectivamente. Se encontró una relación proporcional entre la producción de eritadenina y biomasa. No hubo relación entre el consumo de sustrato y la producción de eritadenina. La fermentación en estado sólido es una alternativa para producir y recuperar la eritadenina.

Palabras clave: hipocolesterolémico, shiitake, soporte sólido

\section{ABSTRACT:}

Background: Lentinula edodes is an edible mushroom of economic importance in Mexico, it produces a cholesterol-reducing compound called eritadenine, which has been obtained from the fruiting body and fungus mycelium. Its production has been evaluated in submerged fermentation, but the solid-state fermentation has not been evaluated.

Objective: Determine if solid state fermentation of $L$. edodes improves the eritadenine production.

Methods: Solid state fermentation was performed using polyurethane foam and an enriched medium to evaluate eritadenine production, growth kinetic and the substrate consumption; the eritadenine was detected by HPLC-DAD at $260 \mathrm{~nm}$.

Results and conclusions: The maximum biomass was $3.6 \pm 0.11 \mathrm{~g} / \mathrm{L}$, with a $0.015 \pm 0.002 \mathrm{~h}^{-1}$ specific growth rate. The eritadenine was produced in the biomass and released to the culture medium; at $168 \mathrm{~h}$ incubation it was increased 2.8 and 2.4 times, respectively. A proportional relationship was found between the eritadenine and biomass production. There was not relationship between substrate consumption and eritadenine production. Solid state fermentation can be an alternative to produce and recover eritadenine.

Keywords: hypocholesterolemic, shiitake, solid support

\section{ARTICLE HISTORY}

Received 04 September 2020 / Accepted 09 June 2021

Published on line: 15 July 2021

\section{CORRESPONDING AUTHOR}

\Lilia Sánchez-Minutti, minutti85@hotmail.com ORCID: 0000-0003-4739-5196 


\section{INTRODUCCIÓN}

La producción mundial de hongos comestibles fue estimada en $3.48 \times 10^{13} \mathrm{~kg}$ para el año 2013, siendo Lentinula edodes (Berk.) Pegler la especie mayormente cultivada (22\%) y correspondiendo a China y Japón las mayores producciones (Royse et al. 2017). En América latina, México destaca por la diversidad de hongos comestibles y en 2001 se reportó una producción de L. edodes de 38,709 toneladas (Martínez-Carrera 2002). La importancia comercial de L. edodes se debe a los beneficios medicinales y nutricionales atribuidos a su consumo y a la obtención de moléculas con actividad biológica como son: antioxidantes, antimicrobianos, antivirales, anticancerígenos e hipocolesterolémicos, entre ellos un compuesto llamado eritadenina (Hobbs 2000). La eritadenina (EA): 2(R), 3(R)-dihidroxi-4-(9-adenil)-ácido butírico, fue identificada en L. edodes por Chibata et al. (1969) y es un compuesto reductor del colesterol (Enman et al. 2008). De acuerdo con Sugiyama et al. (1995) la acción hipocolesterolémica de la EA podría estar relacionada con una modificación del metabolismo de los fosfolípidos hepáticos. Shimada et al. (2003) concluyeron que la EA dietética provoca una acción hipocolesterolémica debido a la modulación de los ácidos grasos y especies moleculares de la lipoproteína plasmática fosfatidilcolina. En ratas con dieta suplementada con L. edodes se observó una reducción en el colesterol total en plasma, triglicéridos, lipoproteínas de baja densidad (LDL), lípidos totales, fosfolípidos y una disminución en la relación LDL/lipoproteínas de alta densidad (Yoon et al. 2011).

La EA también se ha reportado en el cuerpo fructífero de otros hongos comestibles (Ying et al. 2013; Afrin et al. 2016), sin embargo; su obtención a partir de los cuerpos fructíferos puede presentar algunas desventajas, entre ellas, el tiempo de cultivo y el uso de un alimento de consumo humano para la extracción de biomoléculas. La obtención de EA a partir del micelio de los hongos es una propuesta interesante. La biomasa fúngica y algunos metabolitos se han obtenido exitosamente por medio de la fermentación sumergida $(\mathrm{SmF})$ y la fermentación en estado sólido (SSF) (Téllez-Téllez et al. 2008; Álvarez-Cervantes et al. 2013; Velázquez et al. 2014). La SSF puede ser una buena alternativa para obtener biomasa debido a que los hongos crecen naturalmente en sustratos só- lidos, destacando sus bajos costos de capital y gasto energético, menor costo para la recuperación de sus productos (downstream), baja producción de aguas residuales y mayor productividad volumétrica (Gowthaman et al. 2007). La producción de EA en SmF fue evaluada por Enman et al. (2008) quienes reportaron una concentración máxima de $10.04 \mathrm{mg} / \mathrm{L}$ en el caldo de cultivo y $1.05 \mathrm{mg} / \mathrm{g}$ en la biomasa seca. Por otro lado, Enman et al. (2012) suplementaron un medio de cultivo con un extracto acuoso de los residuos del destilado de granos secos para mejorar la producción de EA y reportaron una concentración de $21 \mathrm{mg} / \mathrm{L}$ en SmF. Durán-Rivera et al. (2018) evaluaron diferentes fuentes de carbono, inmovilización y surfactantes para la producción de EA y reportaron hasta 88.06 $\mathrm{mg} / \mathrm{L}$ en un medio líquido con el inóculo inmovilizado con alginato. La producción de EA hasta ahora solo se ha evaluado en SmF y no se ha evaluado en matraces con un soporte sólido como la espuma de poliuretano, por lo tanto, el objetivo de esta investigación fue evaluar la producción de EA en el micelio de L. edodes cultivado en condiciones de SSF.

\section{MATERIALES Y MÉTODOS}

\section{Cepa del hongo}

La cepa de Lentinula edodes H21 en su estado micelial, se obtuvo de la colección de hongos del Laboratorio de Procesos Biotecnológicos de la Universidad Politécnica de Tlaxcala. El hongo fue cultivado en cajas Petri con agar papa dextrosa (PDA) e incubado a $25{ }^{\circ} \mathrm{C}$ por 10 días. El micelio fue utilizado como inóculo para la SSF.

\section{Fermentación en estado sólido}

La SSF se realizó en matraces de $125 \mathrm{~mL}$ que contenían $0.5 \mathrm{~g}$ de espuma de poliuretano cortada en cubos de $5 \mathrm{~mm}^{3}\left(17 \mathrm{~kg} / \mathrm{m}^{3}\right)$, previamente lavada, esterilizada y secada hasta alcanzar peso constante. En cada matraz se agregaron $25 \mathrm{ml}$ del medio de cultivo con la siguiente composición (g/L): glucosa (10), extracto de levadura (5), $\mathrm{KH}_{2} \mathrm{PO}_{4}(0.6), \mathrm{K}_{2} \mathrm{HPO}_{4}(0.4), \mathrm{MgSO}_{4} 7 \mathrm{H}_{2} \mathrm{O}$ (0.5), $\mathrm{FeSO}_{4} 7 \mathrm{H}_{2} \mathrm{O}(0.05), \mathrm{MnSO}_{4} 7 \mathrm{H}_{2} \mathrm{O}(0.05), \mathrm{ZnSO}_{4}$ $7 \mathrm{H}_{2} \mathrm{O}(0.001)$ y $\mathrm{CuSO}_{4} 5 \mathrm{H}_{2} \mathrm{O}(0.25)$, de acuerdo con lo citado por Téllez-Téllez et al. (2008). El medio de cultivo estéril se ajustó a un pH de 6.5. Los matraces se inocularon con 3 discos del crecimiento micelial de L. edodes (5 $\mathrm{mm}$ de diámetro) y se incubaron a $25^{\circ}$ $\mathrm{C}$ por $480 \mathrm{~h}$. 
Cuantificación de la biomasa y consumo de sustrato

El medio de cultivo utilizado como sustrato se separó de la espuma de poliuretano mediante filtración al vacío. La biomasa seca $(X)$ y los parámetros cinéticos (Xmax = biomasa máxima y $\mu=$ la tasa máxima de crecimiento específico) se determinaron según lo establecido por Díaz-Godínez et al., (2001). Los parámetros cinéticos se calcularon con la ecuación logística:

$$
\frac{\mathrm{dX}}{\mathrm{dt}}=\mu\left[1-\frac{\mathrm{X}}{\mathrm{Xmax}}\right] \mathrm{X}
$$

cuando $d X / d t=0$ para $X>0$. La solución de la ecuación logística es la ecuación:

$$
X=\left[\frac{\mathrm{Xmax}}{1+\mathrm{Ce}^{-\mu \mathrm{t}}}\right]
$$

Donde, $\mathrm{C}=(\mathrm{Xmax}-\mathrm{XO}) / \mathrm{X} 0$ y $\mathrm{X}=\mathrm{X} 0$; el valor inicial de biomasa. El consumo de sustrato se determinó en el caldo de cultivo con el ácido 3, 5 dinitrosalicílico, de acuerdo con Miller (1959).

\section{Extracción y cuantificación de EA}

El caldo de cultivo y la espuma de poliuretano con biomasa se utilizaron para la extracción de la EA, tal como lo describieron Enman et al. (2007). La EA se determinó por HPLC-DAD (Perkin Elmer Inc., EUA) a $260 \mathrm{~nm}$ con una columna Supelcosil LC-18 58290 (25 $\mathrm{cm} \times 4.6 \mathrm{~mm} \times 5 \mu \mathrm{m}), 10 \mu \mathrm{L}$ del extracto con EA se inyectó y eluyó con la fase móvil A (ácido trifluoroacético $0.05 \%$ en agua) y $B$ (ácido trifluoroacético 0.05 $\%$ en acetonitrilo) con el siguiente gradiente: $98: 2$ por $5 \mathrm{~min}, 40: 60$ por $10 \mathrm{~min}$ y $98: 2$ por $5 \mathrm{~min}$. Todos los reactivos usados fueron grado HPLC (Sigma Aldrich). El estándar de EA se obtuvo de Synchem UG \& Co. KG (Felsberg, Alemania) y se utilizó para realizar la curva de calibración. La concentración de EA se expresó en mg EA/g de hongo seco o mg EA/L de caldo de cultivo.

\section{Análisis estadístico}

Los resultados se analizaron por ANOVA usando la prueba de Fisher, con el software Statistical Analysis Software (SAS) para determinar las diferencias significativas $(p<0.05)$. Todos los experimentos fueron llevados a cabo con al menos tres réplicas.

\section{RESULTADOS Y DISCUSIÓN}

\section{Producción de biomasa y consumo de sustrato}

El medio de cultivo utilizado como sustrato para la SSF favoreció el crecimiento micelial de L. edodes, alcanzando una biomasa máxima de $3.6 \pm 0.11 \mathrm{~g} / \mathrm{L}$ y una tasa máxima de crecimiento específico de 0.015 $\pm 0.002 \mathrm{~h}^{-1}$ (Figura 1). La fase exponencial del crecimiento comenzó alrededor de las $100 \mathrm{~h}$ y se mantuvo hasta las 320 h, donde comenzó la fase de transición a la fase estacionaria. La fuente de carbono (glucosa) resultó adecuada para el crecimiento de L. edodes. Durante la fermentación, se observó una disminución en la concentración de glucosa en un 54.0 y $86.4 \%$ a las 24 y 72 h de incubación, respectivamente (Figura 2), sin embargo, aunque el sustrato se encontraba casi completamente agotado de las 72 hasta las 480 h, el crecimiento celular continuó. Los carbohidratos son un componente importante del citoesqueleto y un importante requerimiento nutricional para el crecimiento y desarrollo de los hongos superiores (Fazenda et al. 2008). Sin embargo, varios autores han informado que la reducción de la fuente de carbono no siempre limita la producción de biomasa, ya que la generación de ésta puede no tener relación con la cantidad de glucosa asimilada (Enman et al. 2008, Téllez-Téllez et al. 2008), tal como fue el caso observado durante este experimento. Por otro lado, algunos micronutrientes son esenciales para los hongos, como por ejemplo el $\mathrm{Mg}$, un cofactor de reacciones enzimáticas, que estabiliza la membrana plasmática y su consumo es dependiente de ATP (Kim et al. 2005). El medio de cultivo utilizado contenía $\mathrm{Cu}, \mathrm{Mg}, \mathrm{Mn}$, $\mathrm{Zn}$ y $\mathrm{Fe}$, estos micronutrientes pudieron haber tenido un efecto significativo en la producción de enzimas, la absorción de nutrientes y por consiguiente la producción de biomasa. Los compuestos utilizados en un medio de cultivo tienen una influencia sobre la producción de micelio, sin embargo, es importante mencionar que la biomasa no siempre muestra una relación directa con la producción de metabolitos, especialmente con metabolitos secundarios.

El crecimiento micelial de los hongos es un proceso multifactorial, influenciado por el tipo de sustrato, $\mathrm{pH}$ del medio de cultivo, temperatura de incubación, entre otros. De acuerdo con Furlan et al. (1997), el pH óptimo para el crecimiento micelial de L. edodes es 4 , ya que bajo estas condiciones lograron las máximas 

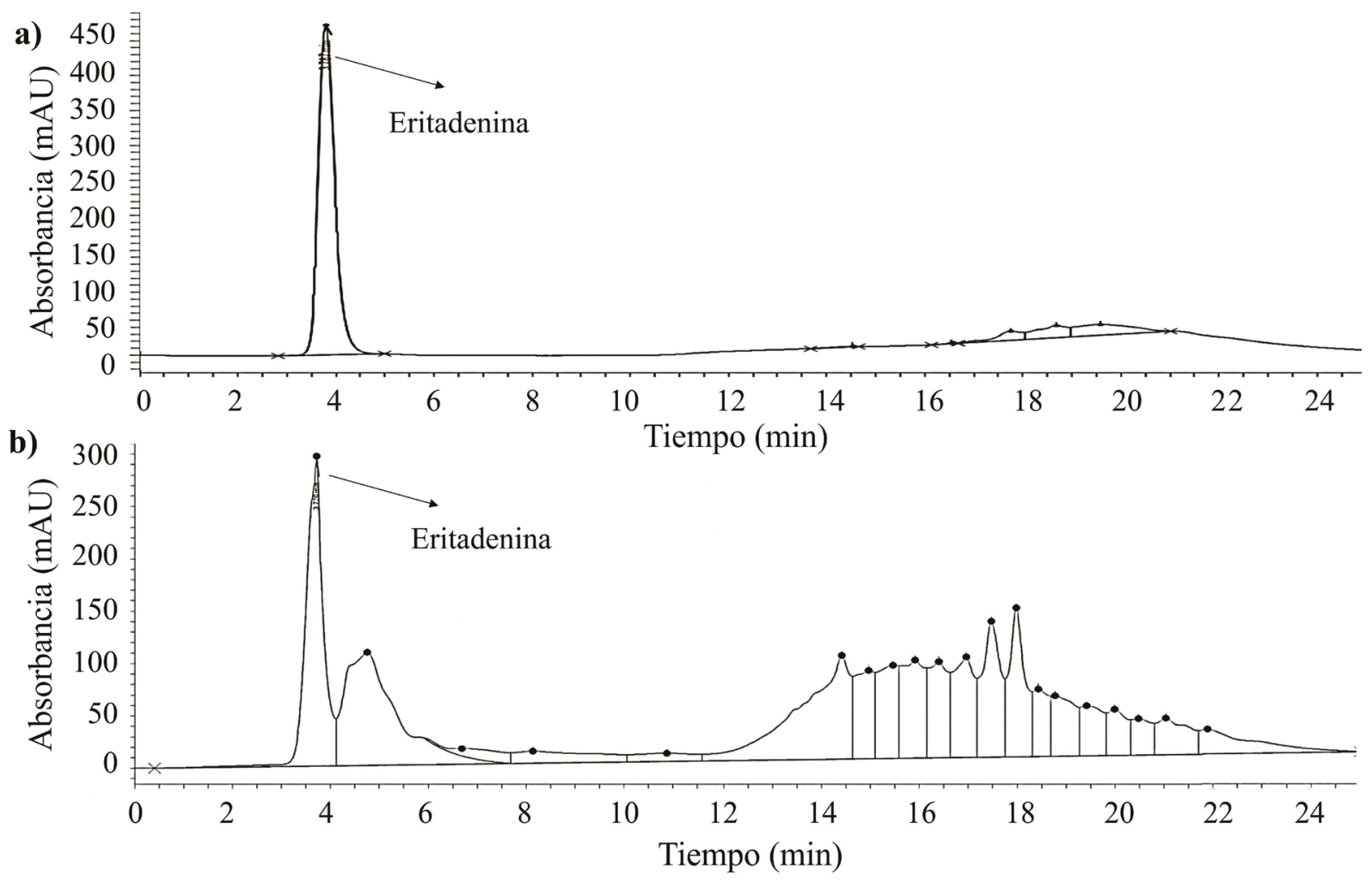

Figura 1. Cromatograma de la eritadenina. a) Estándar de EA. b) EA extraída de la biomasa de Lentinula edodes.

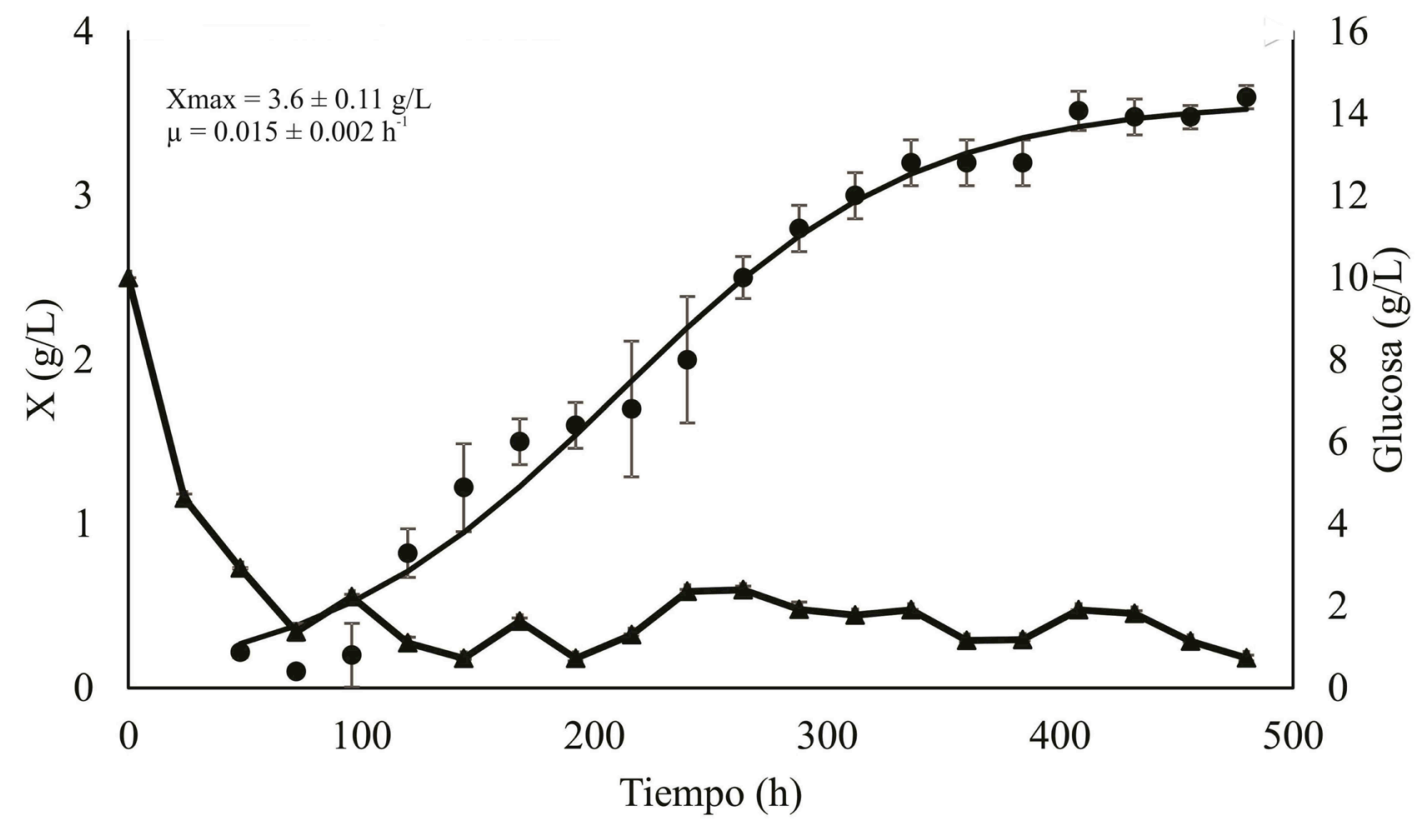

Figura 2. Cinética de crecimiento y consumo de sustrato por Lentinula edodes en fermentación en estado sólido (SSF). • Biomasa experimental. [? Biomasa calculada con el modelo logístico. [? Glucosa. Xmax: biomasa máxima. $\mu=$ velocidad de crecimiento especifico. Las barras de error representan la desviación estándar de tres réplicas. 
tasas de crecimiento del hongo. Por otra parte, Lee et al. (2008) evaluaron el crecimiento de L. edodes en SSF sobre residuos del procesamiento del maíz a diferentes $\mathrm{pH}(4,5$ y 6$)$ y temperaturas $\left(20,25\right.$ y $\left.35^{\circ} \mathrm{C}\right)$, obteniendo el más alto crecimiento micelial a un $\mathrm{pH} 4.7$ y 24.7 ${ }^{\circ} \mathrm{C}$. En este trabajo, el pH inicial del medio de cultivo fue 6.5 y descendió hasta 4.5 después de 480 h de incubación, este parámetro no fue controlado durante la fermentación y su descenso puede ser atribuido a la producción de metabolitos ácidos. Aunque las condiciones iniciales de $\mathrm{pH}$ del presente estudio no fueron iguales a las evaluadas por Furlan et al. (1997) y Lee et al. (2008), al igual que los reportes previos, si se observó crecimiento micelial.

Otro factor que puede afectar el crecimiento de un microorganismo es el sistema de fermentación empleado, (sólido o sumergido), sin embargo, es difícil determinar cuál es mejor, dado que la cantidad de agua, el tipo de hongo, aireación, tamaño de partícula, geometría del biorreactor, nutrientes, entre otros, pueden contribuir al incremento de biomasa u obtención de metabolitos. Feng et al. (2010) evaluaron el crecimiento de $L$. edodes en SmF para la producción de expolisacáridos usando $10 \mathrm{~g} / \mathrm{L}$ de glucosa y $4 \mathrm{~g} / \mathrm{L}$ de levadura y reportaron una biomasa de $3.68 \mathrm{~g} / \mathrm{L}$, resultado similar a lo obtenido en este trabajo con SSF (3.6 g/L). Sin embargo, cuando estos autores incrementaron la fuente de carbono a $15.4 \mathrm{~g}$ y la de nitrógeno a $5.3 \mathrm{~g}$, observaron un incremento de 1.8 veces de biomasa.

La Xmax cuantificada en este trabajo fue más baja que la reportada por Turlo et al. (2008) quienes cultivaron a L. edodes en SmF con diferentes concentraciones de melaza de remolacha, extracto de levadura, extracto de soya y $\mathrm{KH}_{2} \mathrm{PO}_{4}$ y lograron valores de biomasa de 5.3 hasta $10.1 \mathrm{~g} / \mathrm{L}$. La SSF con espuma de poliuretano y el medio de cultivo empleado en este trabajo fueron utilizados para el crecimiento de otra especie comestible, Pleurotus ostreatus (Téllez-Téllez et al. 2008; Velázquez et al. 2014), sin embargo, no había sido utilizado para el crecimiento de $L$. edodes con la finalidad de cuantificar la producción de EA. La biomasa máxima encontrada en este trabajo fue más alta que la reportada por Enman et al. (2008), quienes elaboraron un medio líquido con glucosa, extracto de levadura y malta, y reportaron una producción de EA de 0.34 a $1.77 \mathrm{~g} / \mathrm{L}$; así también, fue más alta que lo reportado por Durán-Rivera et al. (2018), quienes experimentaron con el micelio del hongo inmovilizado en madera y alcanzaron una producción de $1.03 \mathrm{~g} / \mathrm{L}$. Los valores de producción registrados en este estudio son equivalentes a los reportados por Enman et al. (2012) quienes evaluaron la producción de EA suplementando un medio liquido con un extracto y reportaron una biomasa de 1.1 a 3.4 $\mathrm{g} / \mathrm{L}$ en matraces agitados y de $3.2 \mathrm{~g} / \mathrm{L}$ en cajas, pero fue más baja cuando estos autores utilizaron tween 80 en el medio de cultivo $(5.68 \mathrm{~g} / \mathrm{L})$.

Entre las ventajas de utilizar la espuma de poliuretano como soporte inerte, destaca su re-uso después de que esta sea sanitizada, esto ayudaría a reducir el costo del tratamiento inicial que se debe realizar a un sustrato no inerte (selección, lavado, secado, molienda, etc.). La producción de enzimas fúngicas en SSF han demostrado que este proceso, en comparación con la $\mathrm{SmF}$, proporciona mayor productividad volumétrica, es menos propensa a problemas con la inhibición por el sustrato y produce enzimas con mayor estabilidad a la temperatura y pH (Toca-Herrera et al. 2007). Los medios de cultivo utilizados en los bioprocesos tienen varios propósitos, como la producción de biomasa y biomóleculas, sin embargo, no existe un medio universal, por lo cual es necesario dilucidar las interacciones entre los factores que influyen en el crecimiento micelial de L. edodes y la producción de metabolitos.

\section{Eritadenina en la biomasa}

La EA se detectó durante todo el crecimiento micelial, destacando una baja concentración durante las primeras $156 \mathrm{~h}$ de incubación, con valores entre $0.12 \pm 0.02$ hasta $0.25 \pm 0.09 \mathrm{mg} / \mathrm{g}$, después de este tiempo, la EA se incrementó hasta 2.8 veces a las 168 $\mathrm{h}$ de incubación y se mantuvo en el intervalo de 0.49 \pm 0.01 a $0.78 \pm 0.01 \mathrm{mg} / \mathrm{g}$ (Tabla 1). La producción de EA fue iniciada durante la fase exponencial y se mantuvo durante la fase estacionaria. Este mismo fenómeno fue observado por Enman et al. (2008), quienes en un biorreactor de $12 \mathrm{~L}$ reportaron al inicio de la fermentación una producción de $1.7 \mathrm{mg} / \mathrm{L}$ de EA y al final de la incubación de $3.25 \mathrm{mg} / \mathrm{L}$. De acuerdo con Chibata et al. (1969), la EA es un alcaloide de purina. Los alcaloides son metabolitos secundarios cuya producción esta desacoplada del crecimiento celular. En este trabajo, se encontró una relación proporcional entre la producción de EA y biomasa, este mismo fenómeno fue observado por Casas López et al. (2003) quienes evaluaron la producción de lovastatina (una estatina capaz de reducir el colesterol) por 
Aspergillus terreus y reportaron su producción durante todo el crecimiento celular, alcanzando la máxima concentración en la fase estacionaria con una relación proporcional a la concentración de biomasa. Los metabolitos secundarios tales como los alcaloides tienen un papel protector para la célula, pero recientemente se ha descrito que pueden tener una función relacionada con los genes, enzimas y proteínas dentro del organismo, por lo que ha sido difícil entender su función en el metabolismo (Aniszewski 2015) y su producción durante el crecimiento micelial.

La producción de EA por el micelio de L. edodes había sido evaluada previamente en intervalos de $\mathrm{pH}$ de 3.0 a 6.0 (Enman et al. 2008, 2012; Durán-Rivera et al. 2018). Enman et al. (2008) reportaron que la máxima concentración de EA se presentó a pH 5.7, sin embargo, Durán-Rivera et al. (2018) indicaron que el pH presentó una baja correlación con los rendimientos de EA. El crecimiento micelial de shiitake y la producción de ciertas sustancias no siempre tienen el mismo pH de producción (Enman et al. 2008). En este trabajo, la EA se produjo a $\mathrm{pH} 6.5$, sin embargo, la máxima concentración se obtuvo cuando el pH del medio de cultivo descendió a 4.5, coincidiendo con el pH óptimo de crecimiento para $L$. edodes reportado por Lee et al. (2008).

Por otro lado, la fuente de carbono usada en el medio de cultivo tuvo una influencia en la producción de EA, la concentración de glucosa desde las $168 \mathrm{~h}$ hasta las $480 \mathrm{~h}$ de incubación fue baja $(0.73 \pm 0.07$ a $1.9 \pm 0.17 \mathrm{~g} / \mathrm{L})$, pero a partir de este tiempo (168 h) se observó la máxima producción de EA. La concentración de EA a las 168 y 204 h incubación fue de $0.71 \pm 0.01$ a $0.78 \pm 0.01 \mathrm{mg} / \mathrm{g}$, respectivamente, por lo cual, no sería necesario incubar los matraces por más tiempo para recuperar la biomasa y extraer la EA. La máxima concentración de EA encontrada en este trabajo fue más alta que los valores reportados por Enman et al. (2008) quienes en biorreactores con $\mathrm{pH}$ inicial de 5.7 y diferentes velocidades de agitación reportaron 0.16 a $0.50 \mathrm{mg} / \mathrm{g}$, excepto cuando el hongo se cultivó en un biorreactor de $1 \mathrm{~L}$, con pH controlado a 5.7 y una agitación de 250 rpm (1.05 $\mathrm{mg} / \mathrm{g}$ ). Es necesario optimizar la extracción de la EA, dado que el micelio se puede introducir dentro de la espuma de poliuretano y reducir la eficiencia de la extracción con el metanol, requiriendo más volumen o una agitación vigorosa.
Tabla 1. Concentración de eritadenina (EA) en la biomasa de Lentinula edodes y en el medio de cultivo recuperado de la fermentación en estado sólido (SSF)

\begin{tabular}{|c|c|c|}
\hline $\begin{array}{l}\text { Tiempo } \\
\text { (h) }\end{array}$ & biomasa (mg/g) & $\begin{array}{l}\text { EA } \\
\text { medio de cultivo (mg/l) }\end{array}$ \\
\hline 48 & $0.20 \pm 0.10$ * & $11.94 \pm 0.02$ \\
\hline 60 & $0.20 \pm 0.01$ & $14.45 \pm 4.17$ \\
\hline 72 & $0.17 \pm 0.01$ & $16.90 \pm 0.98$ \\
\hline 84 & $0.20 \pm 0.04$ & $13.17 \pm 2.62$ \\
\hline 96 & $0.22 \pm 0.05$ & $13.00 \pm 1.00$ \\
\hline 108 & $0.12 \pm 0.02$ & $15.00 \pm 8.00$ \\
\hline 120 & $0.25 \pm 0.09$ & $31.00 \pm 2.22$ \\
\hline 132 & $0.16 \pm 0.07$ & $17.46 \pm 3.18$ \\
\hline 144 & $0.14 \pm 0.02$ & $16.19 \pm 0.50$ \\
\hline 156 & $0.25 \pm 0.01$ & $36.15 \pm 0.30$ \\
\hline 168 & $0.71 \pm 0.01$ & $88.63 \pm 5.00$ \\
\hline 192 & $0.61 \pm 0.06$ & $63.54 \pm 2.04$ \\
\hline 204 & $0.78 \pm 0.01$ & $75.06 \pm 11.00$ \\
\hline 216 & $0.55 \pm 0.14$ & $63.31 \pm 0.10$ \\
\hline 228 & $0.49 \pm 0.01$ & $82.88 \pm 14.00$ \\
\hline 240 & $0.59 \pm 0.13$ & $67.85 \pm 0.50$ \\
\hline 252 & $0.71 \pm 0.14$ & $88.79 \pm 8.00$ \\
\hline 275 & $0.51 \pm 0.07$ & $76.60 \pm 6.00$ \\
\hline 288 & $0.48 \pm 0.12$ & $89.72 \pm 3.00$ \\
\hline 300 & $0.67 \pm 0.01$ & $83.77 \pm 4.61$ \\
\hline 360 & $0.64 \pm 0.02$ & $85.02 \pm 5.00$ \\
\hline 408 & $0.65 \pm 0.04$ & $97.02 \pm 5.00$ \\
\hline 480 & $0.69 \pm 0.01$ & $80.27 \pm 7.00$ \\
\hline
\end{tabular}

* Media \pm desviación estándar de tres réplicas por experimento.

\section{Eritadenina en el medio de cultivo}

Los matraces usados en la SSF contenían $0.5 \mathrm{~g}$ de espuma de poliuretano y $25 \mathrm{~mL}$ de medio de cultivo, el cual fue absorbido por la espuma durante la fermentación; cuando el medio de cultivo se filtró para cuantificar la biomasa, se recuperó parte del medio de cultivo. La EA se encontró en este medio de cultivo, a las $156 \mathrm{~h}$ de incubación la concentración fue de $36.1 \pm 0.3 \mathrm{mg} / \mathrm{L}$, sin embargo, a las 168 h esta se incrementó hasta 2.4 veces (Tabla 1). La máxima concentración de EA en el medio de cultivo se encontró a las 168, 228, 252, 360 
y 408 h, con un máximo de $97.0 \pm 5.0 \mathrm{mg} / \mathrm{L}$, representando un incremento de 8.12 veces con respecto a la concentración obtenida a las $48 \mathrm{~h}$ de incubación ( $p<$ 0.05). En este trabajo se encontró una concentración de EA más alta que la reportada por Durán-Rivera et al. (2018), quienes experimentaron con diferentes fuentes de carbono, surfactantes y la inmovilización del micelio del hongo logrando cuantificar concentraciones de 8.0 hasta 88.06 mg/L. Por otro lado, Enman et al. (2008, 2012) trabajando en SmF encontraron 10.04 mg/L y 21 $\mathrm{mg} / \mathrm{L}$ de EA, respectivamente, valores que fueron superados con la SSF realizada en este trabajo, ya que la máxima concentración de EA (EA en biomasa + EA en el medio de cultivo) fue de $0.84 \pm 0.01 \mathrm{mg} / \mathrm{g}$ a las 204 h, seguido por $0.81 \pm 0.14$ y $0.80 \pm 0.01 \mathrm{mg} / \mathrm{g}$ a las 252 y $168 \mathrm{~h}$ de incubación, respectivamente (Figura 3).

Los matraces de la SSF no fueron agitados durante la incubación del hongo, sin embargo, la EA se transfirió al medio de cultivo, este fenómeno puede deberse al estrés celular generado durante la fermentación con el soporte sólido. El cultivo estático de L. edodes durante la SSF, no afectó la producción de EA, este mismo fenómeno fue observado por Ansari et al. (2018) quienes indicaron que la agitación tiene un efecto negativo sobre la producción de lovastatina, probablemente por los daños causados en la morfología celular; por el contrario, Enman et al. (2008) reportaron que la agitación generó filamentos miceliales dispersos que favorecieron la excreción de la EA de la célula. Los factores que afectan la producción de metabolitos en SSF o SmF son distintos, dado que la respuesta celular puede ser afectada por el contenido de agua del sistema. Durán-Rivera et al. (2018) indicaron que la inmovilización del micelio fúngico en una matriz de gel de alginato produce cierta protección enzimática cuando las condiciones se vuelven desfavorables, lo cual puede resultar en la biosíntesis de la EA, este mismo efecto puede estar ocurriendo con la espuma de poliuretano utilizada en la SSF. Por lo que la selección del tipo de sustrato y las condiciones fisicoquímicas para la producción de biomasa y EA deben de ser consideradas para obtener mejores rendimientos. Los resultados encontrados en este trabajo indican que la SSF puede ser una alternativa para obtener EA de la biomasa y el medio de cultivo, produciendo una concentración igual o mayor que la reportada en algunos trabajos donde se ha evaluado la SmF.

En conclusión, en esta investigación se demostró que la SSF puede ser una alternativa para la producción de EA por $L$. edodes, lo cual no se había reportado antes. El medio de cultivo utilizado y la espuma de poliuretano fueron adecuados para el crecimiento de L. edodes y el agotamiento de la fuente de carbono no limitó su crecimiento micelial. Durante toda la fermentación se encontró EA tanto en el medio de cultivo como la biomasa, encontrándose una relación proporcional entre la producción de biomasa y EA. Estos resultados brindan una alternativa para obtener EA por medio de la SSF.

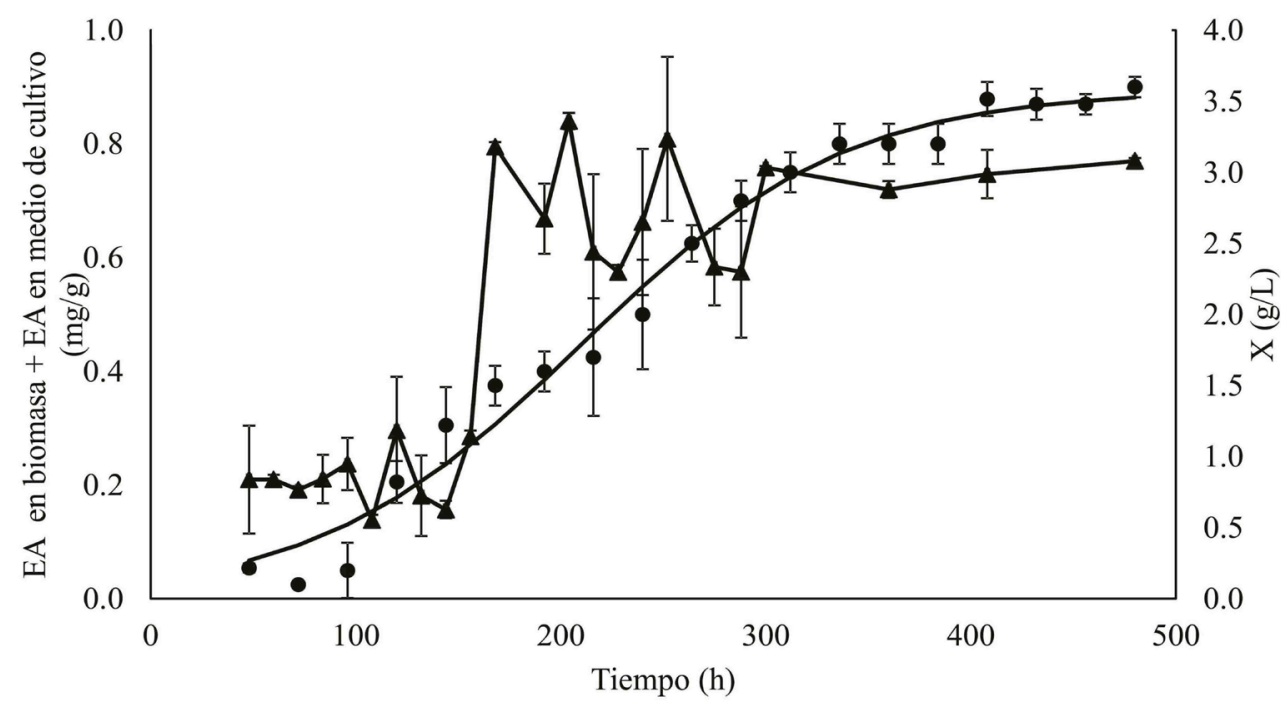

Figura 3. Cinética de crecimiento y producción de EA por L. edodes en fermentación en estado sólido (SSF). • Biomasa experimental. ? 3 Biomasa calculada con el modelo logístico. ? EA en la biomasa + la EA en el medio de cultivo. Las barras de error representan la desviación estándar de tres réplicas. 


\section{AGRADECIMIENTOS}

A la Universidad Politécnica de Tlaxcala (UPTlax) por su apoyo a esta investigación.

\section{LITERATURA CITADA}

Afrin S, Rakib MA, Kim BH, Kim JO, Ha YL. 2016. Eritadenine from edible mushrooms inhibits activity of angiotensin converting enzyme in vitro. Journal of Agricultural and Food Chemistry 64, 11, 2263-2268. https://doi.org/10.1021/acs.jafc.5b05869

Aniszewski T. 2015. Alkaloids: chemistry, biology, ecology and applications. Elsevier. Amsterdam.

Álvarez-Cervantes J, Hernández-Domínguez EM, Arana-Cuenca A, Díaz-Godínez G, Mercado-Flores Y. 2013. Purification and characterization of xylanase SRXL1 from Sporisorium reilianum grown in submerged and solid-state fermentation. BioResources 8, 5309-5318. https://doi.org/10.15376/biores.8.4.5309-5318

Ansari FJ, Jalili H, Bizukojc M, Amrane A. 2018. Optimization of date syrup as a novel medium for lovastatin production by Aspergillus terreus ATCC 20542 and analyzing assimilation kinetic of carbohydrates. Annals of Microbiology 68, 351-363. https://doi. org/10.1007/s13213-018-1342-2

Casas López JL, Sánchez Pérez JA, Fernández Sevilla JM, Acién Fernández FG, Molina E, Chisti Y. 2003. Production of lovastatin by Aspergillus terreus: effects of the $\mathrm{C}: \mathrm{N}$ ratio and the principal nutrients on growth and metabolite production. Enzyme and Microbial Technology 33, 270-277. https://doi.org/10.1016/S01410229(03)00130-3

Chibata I, Okumura K, Takeyama S, Kotera K. 1969. Lentinacin: A new hypocholesterolemic substance in Lentinus edodes. Experientia 25, 1237-1238. https://doi.org/10.1007/BF01897467

Díaz-Godínez G, J Soriano-Santos, C Augur, G Viniegra-González, 2001. Exopectinases produced by Aspergillus niger in solid-state and submerged fermentation: A comparative study. Journal of Industrial Microbiology and Biotechnology 26, 271-275. https:// doi.org/10.1038/sj.jim.7000113

Durán-Rivera B, Moreno-Suárez JR, Rojas Rodas F, Valencia Jiménez KM, Castro-Restrepo D. 2018. Enhancement of eritadenine production using three carbon sources, immobilization and surfactants in submerged culture with shiitake mushroom (Lentinula edodes) (Berk.) Singer. African Journal of Food Science 12, $374-$ 382. https://doi.org/10.5897/AJFS2017.1654

Enman J, Hodge D, Berglund KA, Rova U. 2008. Production of the bioactive compound eritadenine by submerged cultivation of shiitake (Lentinus edodes) mycelia. Journal of Agricultural and Food Chemistry 56, 2609-2612. https://doi.org/10.1021/ jf800091a

Enman J, Hodge D, Berglund KA, Rova U. 2012. Growth promotive conditions for enhanced eritadenine production during submerged cultivation of Lentinus edodes. Journal of Chemical Technology and Biotechnology 87, 903-907. https://doi. org/10.1002/jctb.3697

Enman J, Rova U, Berglund KA. 2007. Quantification of the bioactive compound eritadenine in selected strains of shiitake mushroom (Lentinus edodes). Journal of Agricultural and Food Chemistry 55, 1177-1180. https://doi.org/10.1021/jf062559
Fazenda ML, Seviour R, McNeil B, Harvey LM. 2008. Submerged Culture Fermentation of "Higher Fungi": The Macrofungi. Advances in Applied Microbiology 63, 33-103. https://doi.org/10.1016/ s0065-2164(07)00002-0

Feng YL, Li WQ, Wu XQ, Cheng JW, Ma SY. 2010. Statistical optimization of media for mycelial growth and exo-polysaccharide production by Lentinus edodes and a kinetic model study of two growth morphologies. Biochemical Engineering Journal 49, 104112. https://doi.org/10.1016/j.bej.2009.12.002

Furlan S, Virmond L, Miers D, Bonatti M, Gern R, Jonas R. 1997. Mushrooms strains able to grow at high temperatures and low $\mathrm{pH}$ values. World Journal of Microbiology and Biotechnology 13, 689-92. https://doi.org/10.1023/A:1018579123385

Gowthaman MK, Krishna C, Moo-Young M. 2007. Fungal solid state fermentation-an overview. Applied Mycology and Biotechnology 1, 305-352.https://doi.org/10.1016/s1874-5334(01)80014-9 Hobbs CR. 2000. Medicinal value of Lentinus edodes (Berk.) Sing. (Agaricomycetideae). A literature review. International Journal of Medicinal Mushrooms 2, 287-302. https://doi.org/10.1615/ IntJMedMushr.v2.i4.90

Kim HO, Lim JM, Joo JH, Kim SW, Hwang HJ, Choi JW, Yun JW. 2005. Optimization of submerged culture condition for the production of mycelial biomass and exopolysaccharides by Agrocybe cylindracea. Bioresource Technology 96, 1175-1182. https://doi.org/10.1016/j.biortech.2004.09.021

Lee S, Bae H, Kim N, Hwang S. 2008. Optimization of growth conditions of Lentinus edodes mycelium on corn processing waste using response surface analysis. Journal of Bioscience and Bioengineering 105, 161-163. https://doi.org/10.1263/jbb.105.161

Martinez-Carrera D. 2002. Current development of mushroom biotechnology in Latin America. Micología Aplicada International 14, 61-74.

Miller GL. 1959. Use of dinitrosalicylic acid reagent for determination of reducing sugar. Analytical Chemistry 31, 426-428. https://doi. org/10.1021/ac60147a030

Royse DJ, Baars J, Tan Q. 2017. Current overview of mushroom production in the world. In: Zied DC, Pardo-Giménez A (ed.), Edible and medicinal mushrooms. John Wiley \& Sons, New York. 5-13. https://doi.org/10.1002/9781119149446.ch2

Shimada Y, Morita T, Sugiyama K. 2003. Eritadenine-induced alterations of plasma lipoprotein lipid concentrations and phosphatidylcholine molecular species profile in rats fed cholesterol-free and cholesterol-enriched diets. Bioscience, Biotechnology, Biochemistry 67, 996-1006. https://doi.org/10.1271/bbb.67.996

Sugiyama K, Akachi T, Yamakawa A. 1995. Hypocholesterolemic action of eritadenine is mediated by a modification of hepatic phospholipid metabolism in rats. The Journal of Nutrition 12, 2134-2144. https://doi.org/10.1093/jn/125.8.2134

Téllez-Téllez M, Fernández FJ, Montiel-González AM, Sánchez C, Díaz-Godínez G. 2008. Growth and laccase production by Pleurotus ostreatus in submerged and solid-state fermentation. Applied Microbiology and Biotechnology 81, 675-679. https:// doi.org/10.1007/s00253-008-1628-6

Toca-Herrera J, Osma J, Couto S. 2007. Potential of solid-state fermentation for laccase production. Communicating Current Research and Educational Topics and Trends in Applied Micro- 
biology 10, 391-400. http://www.formatex.org/microbio/pdf/ Pages391-400.pdf

Turlo J, Gutkowska B, Herold F, Krzyczkowski W, Błazewicz A, Kocjan R. 2008. Optimizing vitamin B12 biosynthesis by mycelial cultures of Lentinula edodes (Berk.) Pegler. Enzyme and Microbial Technology 43, 369-374. https://doi.org/10.1016/j. enzmictec.2008.05.005

Velázquez L, Téllez-Téllez M, Díaz R, Bibbins-Martínez MD, Loera O, Sánchez C, Tlecuitl-Beristain S, Díaz-Godínez G. 2014. Laccase isoenzymes of Pleurotus ostreatus grown at different $\mathrm{pH}$ in Solid-State Fermentation using polyurethane foam as support. Annual Research and Review in Biology 4, 2566-2578. https:// doi.org/10.9734/arrb/2014/10016
Ying X, Ma J, Liang Q, Wang Y, Bai G, Luo G. 2013. Identification and analysis of the constituents in an aqueous extract of Tricholoma matsutake by HPLC coupled with diode array detection/electrospray ionization mass spectrometry. Journal of Food Science 78, 1173-1182. https://doi.org/10.1111/1750-3841.12219

Yoon KN, Alam N, Lee JS, Cho HJ, Kim HY, Shim MJ, Lee MW, Lee TS. 2011. Antihyperlipidemic effect of dietary Lentinus edodes on plasma, feces and hepatic tissues in hypercholesterolemic rats. Mycobiology 39, 96-102. https://doi.org/10.4489/ MYCO.2011.39.2.096 